
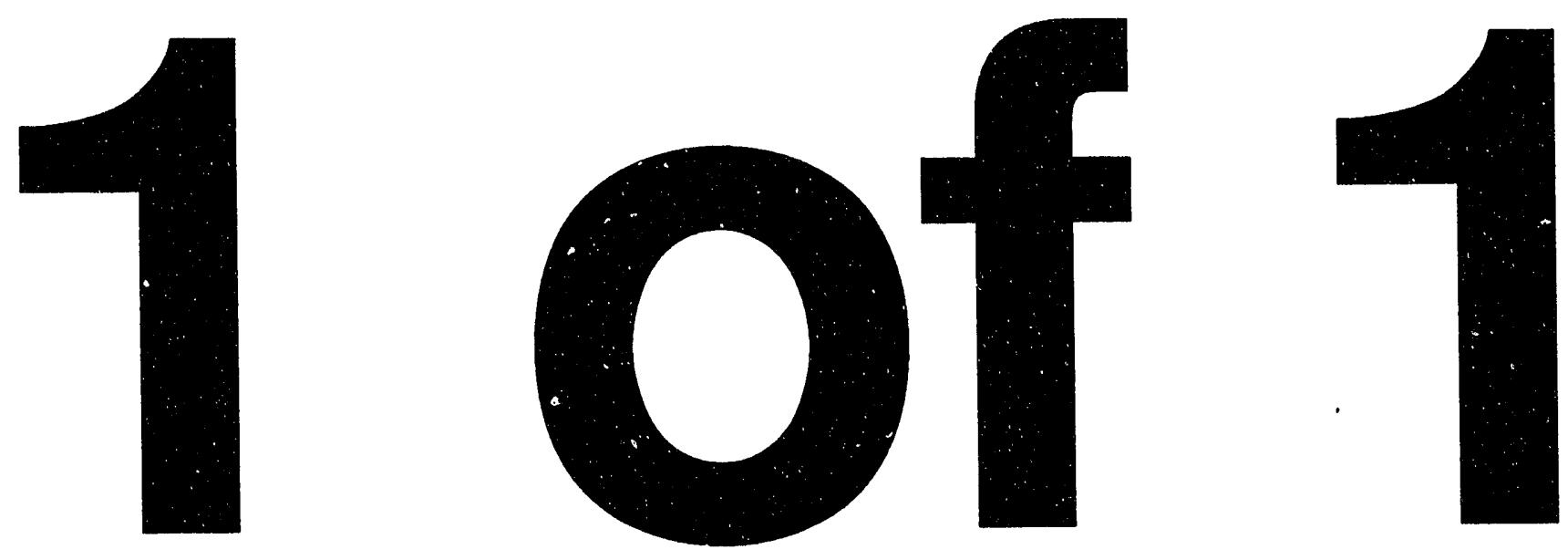


\section{DESIGN OF LARGE APERTURE, LOW MASS VACUUM WINDOWS*}

W. J. Leonhardt and M. Mapes

AGS Department, Brookhaven National Laboratory

Associated Universities, Inc.

Upton, New York 11973

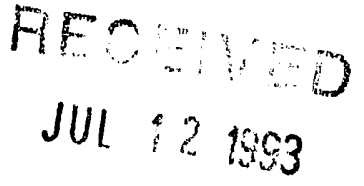

\section{Abstract}

Large vacuum vessels are employed downstream of fixed targets in High Energy Physics experiments to provide a long path for particles to traverse without interacting with air molecules. These vessels generally have a large aperture opening known as a "vacuum window" which employs a thin membrane to preserve the vacuum environment yet allows the particles to pass through with a minimal effect on them. Several large windows have been built using a composite of Kevlar/Mylar including circular windows to a diameter of $96.5 \mathrm{~cm}$ and rectangular windows up to $193 \mathrm{~cm} \mathrm{x} 86 \mathrm{~cm}$. This paper describes the design, fabrication, testing and operating experience with these windows and relates the actual performance to theoretical predictions.

\section{INTRODUCTION}

Some experimental beam lines at Brookhaven National Laboratory require large aperture, low mass vacuum windows to minimize beam loss and reduce background radiation in close proximity to beam detectors. These vacuum windows are essentially a wall or membrane separating a vacuum space from atmosphere through which the beam passes, and they exhibit a vacuum integrity which allows them to be used in vacuum systems with a pressure of $10^{-4}$ Torr. The material used for the windows must be thin and light enough so as to have the minimum effect on the beam, and, at the same time, be thick and strong enough to operate reliably and safely. In the past, small aperture windows used Mylar as the window material. Mylar has a reasonably high tensile strength, good vacuum properties, and its density is acceptable for the thicknesses required in small aperture windows. As the apertures get larger, the thickness of the window material must increase, so Mylar becomes less attractive. In addition, Mylar is not available in thicknesses greater than $0.36 \mathrm{~mm}$; therefore, if used in large aperture windows, multiple layers would be required.

To create a window with a mass lower than Mylar, designs have emerged which use a composite of a thin sheet of Mylar and a reinforcing fabric. Reinforcing fabrics are available with tensile strengths an order of magnitude greater than Mylar; therefore, smaller thicknesses are required for a given apersure. However, Mylar in thin sheets is still used since the fabrics cannot achieve any sort of a vacuum seal. Various reinforcing fabrics have been tried including carbon (graphite)[1], polyester fiber (Dacron)[2][3], and aramid

* Work performed under the auspices of the U.S. Department of Energy. fiber (Kevlar)[3][4], and, after reviewing the results, it was judged that Kevlar was the best candidate to develop for designs at Brookhaven National Laboratory (BNL). Typical window materials are shown in Table I. To date, four large aperture windows have been constructed and tested at BNL including two circular windows of $91.4 \mathrm{~cm}$ and $96.5 \mathrm{~cm}$ diameter and two rectangular windows measuring $61 \mathrm{~cm} \mathrm{x}$ $122 \mathrm{~cm}$ and $86 \mathrm{~cm} \mathrm{x} 193 \mathrm{~cm}$.

\section{DESIGN AND FABRICATION}

Current window designs used at BNL generally follow the technique first introduced by Fermi National Accelerator Lab. [4] The window composite is a combination of Kevlar 29 and Mylar type A sized appropriately for the specific window aperture. Components of a typical window assembly are shown in Fig. 1.

In assembling the window, a Viton O-ring is inserted into the vacuum window flange. Next an annular sheet of Mylar (Mylar ring) is used whose inner and outer dimensions are the same as the window clamp flange. Over the Mylar ring goes a full sheet of Kevlar and a full sheet of Mylar. Next comes the window clamping flange which also has an O-ring groove. In this groove is an O-ring of 1100 -T0 aluminum. This aluminum O-ring aids in clamping the composite window materials since earlier windows experienced premature failure due to pullout from the flange. When assembling the window, the area opposite the Viton O-ring is marked on both the Kevlar and Mylar pieces. The Mylar is roughened with sand paper on the surface facing the Kevlar and the Kevlar is painted with a bead of epoxy in the same area. Care must be taken so that the epoxy doesn't spread appreciably in the plane of the window. The window assembly is then bolted together and properly torqued. When the epoxy cures, a vacuum tight seal is formed which prohibits edge leaking of the composite material. The epoxy mix used is formulated to be flexible and to soak well into the Kevlar providing a vacuum seal with no problems. [5] The final sizes of the materials used in the windows at $\mathrm{BNL}$ are as follows:

$\begin{array}{llll}\text { Aperture } & \begin{array}{l}\text { Kevlar } \\ \text { Thicknes }\end{array} & \begin{array}{l}\text { Mylar } \\ \text { Thickness }\end{array} & \begin{array}{c}\text { Composite } \\ \text { Mass }\end{array} \\ \phi 91.4 \mathrm{~cm} & 0.43 \mathrm{~mm} & 0.13 \mathrm{~mm} & 0.05 \mathrm{~g} / \mathrm{cm}^{2} \\ \phi 96.5 \mathrm{~cm} & 0.43 \mathrm{~mm} & 0.13 \mathrm{~mm} & 0.05 \mathrm{~g} / \mathrm{cm}^{2} \\ 122 \times 61 \mathrm{~cm} & 0.30 \mathrm{~mm} & 0.05 \mathrm{~mm} & 0.03 \mathrm{~g} / \mathrm{cm}^{2} \\ 193 \times 86 \mathrm{~cm} & 0.43 \mathrm{~mm} & 0.05 \mathrm{~mm} & 0.04 \mathrm{~g} / \mathrm{cm}^{2}\end{array}$

The circular windows represent the earliest use of this type of window at BNL and thus the thicknesses and composite mass reflect a very conservative design. The material thicknesses for the $\phi 91.4$ window were determined by testing and, since 
$\checkmark$ a large enough safety margin was present, these thicknesses were judged adequate for $\$ 96.5$ window as well. Confidence gained with the use of the circular windows allowed the rectangular windows to be designed with a lower composite mass. As a comparison, if the $122 \times 61 \mathrm{~cm}$ window was made only of Mylar, its thickness would be $1.4 \mathrm{~mm}$ and its mass would be $0.19 \mathrm{~g} / \mathrm{cm}^{2}$; therefore, the composite window has a mass only $15 \%$ of a pure Mylar window.

\section{SAFETY CONSIDERATIONS}

Safety regulations require that a vacuum window shall be cycled three times at $50 \%$ over operating pressure to demonstrate its integrity in going from load to no load conditions; however, since the behavior of Kevlar fabric does not follow theoretical predictions, a cycling pressure of $100 \%$ over operating pressure is used. These vacuum windows are typically used on large vacuum vessels, and considerable shock wave would result in the event of a total window failure. When Mylar is used alone as a window material, experience has shown that failure of the Mylar is similar to a balloon breaking and the resulting shock wave a sizeable threat to life and property. All composite window designs used at BNL are hydrostatically tested to failure to indicate the margin of safety present in one atmosphere operation; however, it was felt that a hydrostatic test might not correctly model a catastrophic failure so a full scale test was conducted. The $\phi 91.4 \mathrm{~cm}$ window assembly was attached to a vacuum vessel with an internal volume of over 3100 liters and the vessel pumped down to $10^{-3}$ Torr. A weighted pendulum with a sharp point was positioned in front of the window and swung in puncturing the window in the center. While the Mylar split across the full aperture, the Kevlar only suffered a hole the size of the puncturing elements and the tank bled up to atmosphere in a slow, gentle fashion.

\section{TESTING}

All window designs have been hydrostatically tested to failure in addition to the cycle test described in the previous section using a test fixture. The window assembly was bolted to the fixture as shown in Fig. 2 so that when pressurized with water, the window is stressed in the same direction as it is in experimental use. A pressure gauge was used to monitor the pressure applied to the window, and a dial indicator was placed in the center of the window to record the deflection of the window as pressure was applied to it.

Tests were conducted for various combinations of Kevlar and Mylar on the $\phi 91.4 \mathrm{~cm}$ circular and both rectangular windows. The results are summarized in Table II. All the tests were carried out using a Kevlar 29 fabric except the one where the Kevlar thickness is $0.25 \mathrm{~mm}$. This thickness was Kevlar 49 since it was not available in Kevlar 29. Kevlar 29 is preferred over Kevlar 49 since it has a lower elastic modulus while having the same tensile strength. This is more desirable in window applications where the greater deflection aids in lowering the slippage or pull out forces. The test windows using Kevlar 29 had no short term c: epage. Long term creepage needs more study.

Window failure in both the circular and rectangular windows was of the classic thin membrane failure type, with the windows rupturing along their edges.

\section{THEORETICAL PREDICTIONS}

Classical equations used in predicting window performance are given by Timeoshenko[6] as:

$$
\begin{gathered}
S=Z\left[E\left(\frac{p a}{t}\right)^{2}\right]^{1 / 3} \\
w=K\left[\frac{p a^{4}}{E t}\right]^{1 / 3}
\end{gathered}
$$

where $\quad w=$ window deflection $S=$ stress

$$
\mathrm{p}=\text { pressure } \quad \mathrm{E}=\text { Young's modulus }
$$

$\mathrm{t}=$ window thickness

$a=$ circular diameter or short side of rectangle

$\mathrm{Z}=$ geometric constant $=0.27$ for circular 0.34 for rectangular

$\mathrm{K}=$ geometric constant $=0.26$ for circular 0.36 for rectangular

Using these equations has shown that they do not predict actual performance very closely, and testing is required to safely size and optimize the window materials. For example, looking at the Kevlar alone, catalog values of initial material properties give window deflection calculations that are lower than observed while measured values of material properties give calculations higher than observed. Several factors may contribute to the anaiytical and material property uncertainties and it is believed that most of them are due to the woven nature of the Kevlar.[5]

The above analytical expressions have been used with some success, however. If Eq. (2) is used to compute an "apparent pressure" using the deflection at failure and the properties for Mylar, that value can be used in Eq. (1) to compute an "apparent stress" on the Mylar at failure, again using Mylar properties. This apparent stress at failure compares reasonably well to the tensile strength of the Mylar; therefore it is felt that at actual operating deflections, the stress level in the Mylar can be computed, and an operating factor of safety can be determined.

\section{OPERATING EXPERIENCE}

Both circular windows have been installed in experimental beam lines. The $\phi 9.41 \mathrm{~cm}$ window was used in an experiment which ran about six months. The vacuum was maintained at less than $10^{-3}$ Torr and, although the window was cycled about fives times, no problems were encountered. The $\phi 96.5 \mathrm{~cm}$ window ran for four six month periods. Initial 
- problems were encountered when the window was cycled since, after a few cycles, the window developed slow leaks. The leaks appear to have been caused by an older epoxy formulation which was not as flexible as the one currently used. Since the formulation has been changed, the window has run without problems at vacuum levels of $10^{-5}$ Torr. The rectangular :vindows are a new design and operating experience is not yet available.

In summary, the design of the Kevlar/Mylar composite windows has been further developed at BNL. These windows have been effectively used as a low mass alternative to Mylar alone and have been shown to be both safe and reliable.

\section{REFERENCES}

[1] Takao Inagaki, National Laboratory for High Energy Physics (KEK), Japan, private communication, 1992.

[2] J.E. Walter, "Large Rectangular Vacuum Windows," Trans. IEEE, 1973, p. 125.

[3] R.M. Reimers, J. Porter, J. Meneghett, S. Wilde, and R. Miller, A $344 \mathrm{~cm} \times 86 \mathrm{~cm}$ Low Mass Vacuum Window, Lawrence Berkeley Lab. Report No. LBL-15991, 1983.

[4] S. Sobczynski, E732/E621 Cloth Vacuum Window Design Report, Fermi National Accelerator Laboratory, private communicaticn, 1986.

[5] M. Mapes and W.J. Leonhardt, "Design of Large Aperture, Low Mass Vacuum Windows," to be published in Vacuum Science and Technology A, Vol II, Aug. 1993.

[6] S. Timoshenko and S. Woirowsky-Kriegher, Theory of Plates and Shells, McGraw Hill, N.Y., 2/e, 1959.

Dacron and Kevlar are registered trademarks of E.I. Dupont DeNemours and Co., Inc.

TABLE I - Typical Window Materials

\begin{tabular}{||l|l|l|l||}
\hline Material & $\begin{array}{l}\text { Tensile } \\
\text { Strength } \\
\mathrm{MPa}\end{array}$ & $\begin{array}{l}\text { Modulus* } \\
\mathrm{MPa}\end{array}$ & $\begin{array}{l}\text { Density } \\
\mathrm{g} / \mathrm{cm}^{3}\end{array}$ \\
\hline Kevlar 39 & 2,760 & $\begin{array}{l}62,000 \\
(8,200)\end{array}$ & $\begin{array}{l}1.44 \\
(0.736)^{* *}\end{array}$ \\
\hline Kevlar 49 & 2,760 & $\begin{array}{l}117,000 \\
(18,000)\end{array}$ & $\begin{array}{l}1.44 \\
(0.736)\end{array}$ \\
\hline Dacron & 1,120 & 13,800 & 1.38 \\
\hline $\begin{array}{l}\text { Stainless } \\
\text { Steel 304 }\end{array}$ & $580-1,276$ & 200,000 & 7.83 \\
\hline $\begin{array}{l}\text { Aluminum } \\
\text { 6061 T6 }\end{array}$ & 310 & 69,000 & 2.70 \\
\hline Mylar & 172 & $\begin{array}{l}3,450 \\
(5000)\end{array}$ & 1.40 \\
\hline
\end{tabular}

Catalog values shown; actual measured values--parenthesis.

**Density given is for individual strands and values in parenthesis are apparent density for woven material.

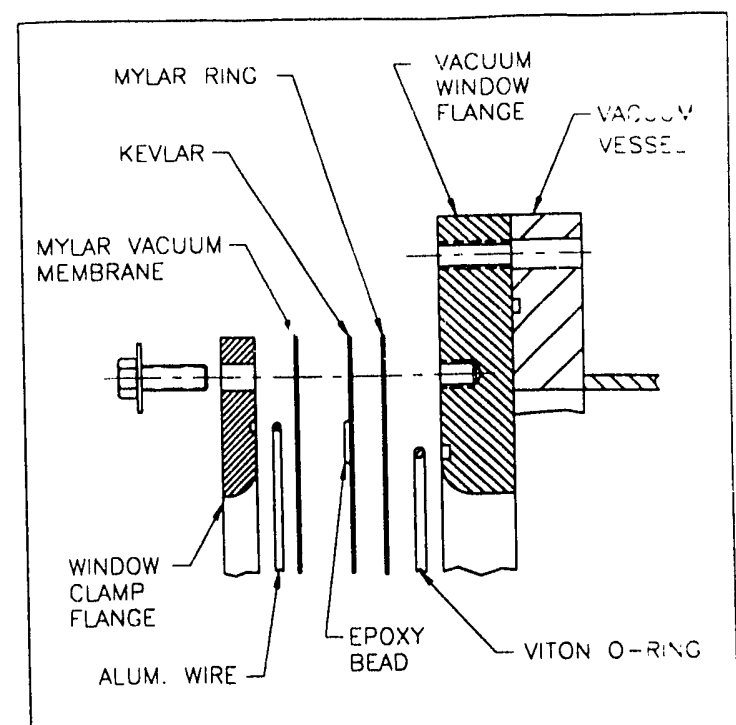

Figure 1 TYPICAL WINDOW ASSEMB: ${ }^{2}$

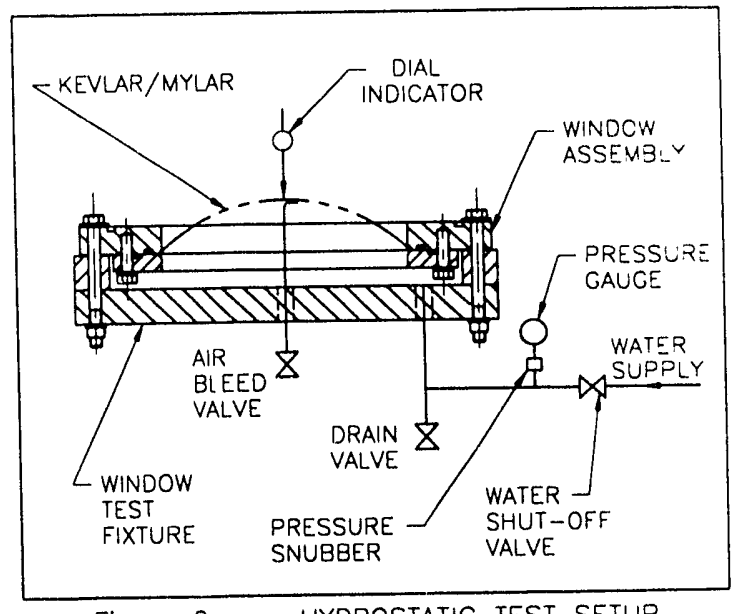

Figure 2 HYDROSTATIC TEST SETUP

TABLE II

\begin{tabular}{||c|c|l|l||}
\hline $\begin{array}{l}\text { Test } \\
\text { No }\end{array}$ & Window Size & $\begin{array}{l}\text { Thickness, } \\
\text { Kevlar/Mylar }\end{array}$ & $\begin{array}{l}\text { Pressure at } \\
\text { Failure }\end{array}$ \\
\hline \hline 1 & 91.4 circular & $0.58 / 0.13 \mathrm{~mm}$ & $4.1 \mathrm{~atm}$ \\
2 & " & $0.43 / 0.13$ & 4.1 \\
3 & " & $0.30 / 0.13$ & 2.0 \\
4 & $122 \times 61$ rect. & $0.38 / 0.13$ & 3.2 \\
5 & " & $0.30 / 0.13$ & 2.5 \\
6 & " & $0.30 / 0.05$ & 2.3 \\
7 & " & $0.25 / 0.13 *$ & 1.5 \\
8 & $193 \times 86$ rect. & $0.30 / 0.05$ & $* * 43 / 0.13$ \\
9 & " & $0.43 / 0.05$ & 2.7 \\
10 & " & $0.30 / 0.05$ & 2.5 \\
11 & \multicolumn{3}{|l}{} \\
\hline
\end{tabular}

* Kevlar 49 used this test only; all others Kevlar 29.

** Not taken to failure, long term cycle test. 


\section{DISCLAIMER}

This report was prepared as an account of work sponsored by an agency of the United States Government. Neither the United States Government nor any agency thereof, nor any of their employees, makes any warranty, expiess or implied, or assumes any legal liability or responsibility for the accuracy, completeness, or usefulness of any information, apparatus, product, or process disclosed, or represents that its use would not infringe privately owned rights. Reference herein to any specific commercial product, process, or service by trade name, trademark, manufarturer, or otherwise does not necessarily constitute or imply its endorsement, recommendation, or favoring by the United States Government or any agency thereof. The views and opinions of authors expressed herein do not necessarily state or reflec: those of the United States Government or any agency thereof. 

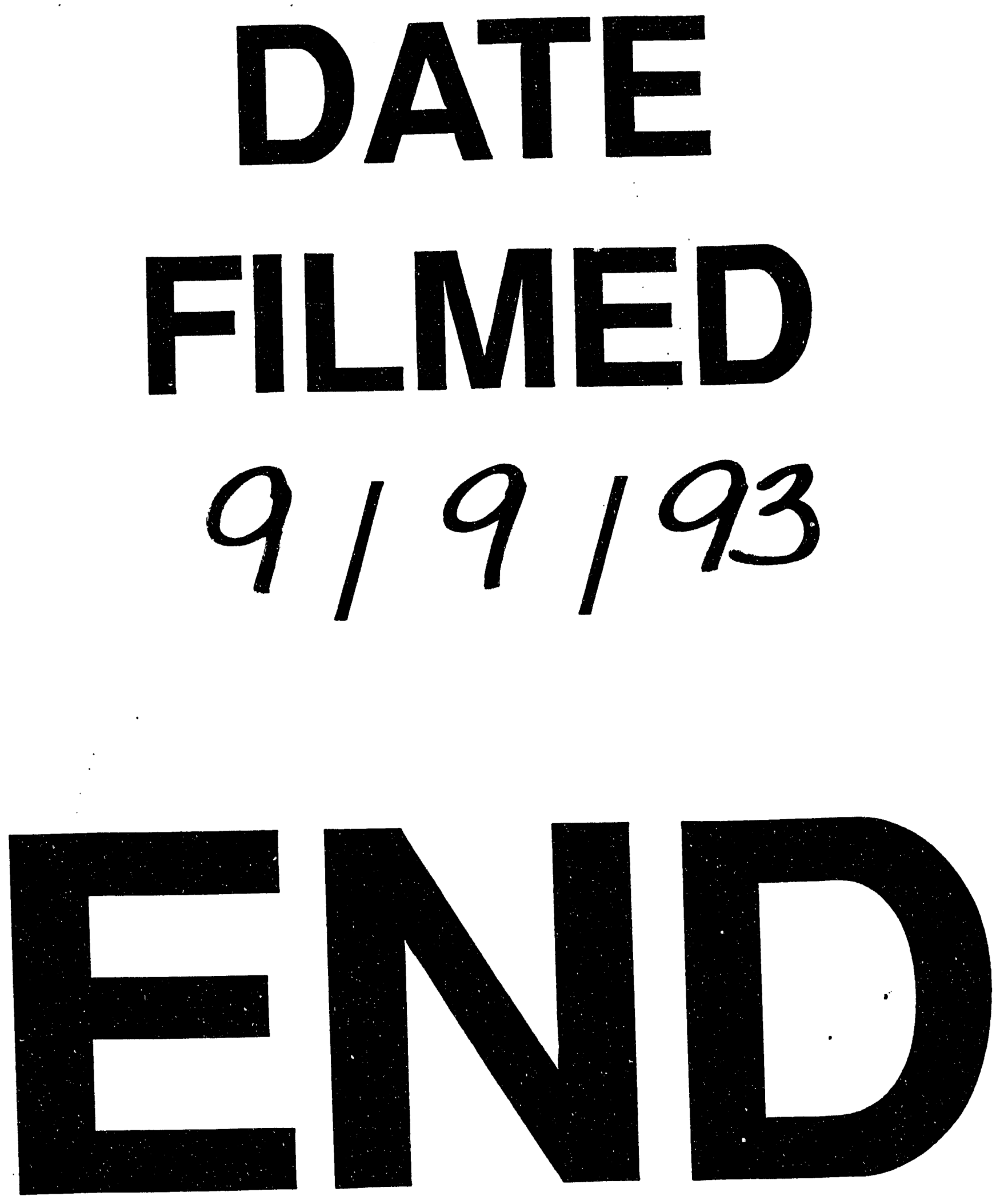
